\title{
Recall intervals in children are individualized and extended
}

\section{Recall intervals and caries}

\author{
Authors \\ ${ }^{1}$ Løken, Sonja Yr \\ E-mail: s.y.loken@odont.uio.no \\ ${ }^{1 \dagger}$ Wigen, Tove Irene \\ E-mail: tove.wigen@odont.uio.no \\ ${ }^{1 \dagger}$ Wang, Nina Johanne \\ E-mail: n.j.wang@odont.uio.no \\ ${ }^{1}$ Department of Pediatric Dentistry and Behavioral Science \\ Institute of Clinical Dentistry \\ University of Oslo, Norway \\ $\dagger$ Equal contributors
}

\section{Corresponding author}

Sonja Yr Løken

Institute of Clinical Dentistry

Box 1109 Blindern

0317 Oslo, Norway

E-mail: s.y.loken@odont.uio.no

Phone: +4722852000

Number of figures: 2

Number of tables: 4 


\section{Abstract}

Objective: The aim of this study was to follow attendance patterns longitudinally by exploring length of intervals between routine dental examinations in children at the ages of 5 and 12 years, and study associations between length of recall intervals and caries prevalence, controlled for gender, parent's background and parent's education. Material and methods: The study included 2960 children in one Norwegian county monitored from 5 to 12 years of age. Data were collected at clinical examinations, from dental records and by parental questionnaires. Length of recall intervals was dichotomized into short (shorter than 18 months) and long (18 months and longer). Data were analyzed and tested using Chi-square statistics, correlation coefficient and multivariate regression. The study was ethically approved. Results: Recall intervals were individualized and varied from 4 to 30 months. The most frequent used recall intervals were 12, 18, 20 and 24 months. A majority of children at both ages were given long recall intervals. Multivariate logistic regression showed that the probability of having short interval was higher in children having caries experience than in caries-free children at both 5 years (OR 12.6 CI 9.9-16.0) and 12 years (OR 2.7 CI 2.3-3.1). At 5 years of age, length of recall intervals was associated with parents' background (OR 1.8 CI 1.4-2.4) and parents' education (OR 1.3 CI 1.0-1.5). Conclusions: The results showed that routine intervals were individualized and extended, indicating that more resources were spent on children with the highest need of dental care, aiming at reducing health inequalities. 


\section{Keywords}

Attendance pattern, caries risk assessment, routine dental examinations, optimal oral health care, resource allocation 


\section{Introduction}

Recall routines in dental care have consequence for patients, dental personnel and policymakers. Traditionally 6-month recall intervals have been advocated by health authorities and dental personnel [1]. Four decades ago, Sheiham initiated debate about length between recall intervals [2]. The rationale behind 6-monthly recall interval was questioned, and it was argued that this routine might lead to overtreatment and waste of resources. Recently it has been suggested in many countries that standardized recall intervals are inappropriate and that recall intervals should be individualized based on risk assessment [3-7]. Since the 1990s, intervals between routine examinations in the dental services have gradually been extended and individualized in the Scandinavian countries concurrent with improvements in oral health [8$10]$.

In countries displaying skewed caries distribution, a shift from population-based interventions to individual routines in children may be favorable in order to optimize costeffectiveness [11]. The rationale for individualized recall intervals is to deliver dental care according to the child's oral health. Individualizing the length of recall intervals is reasonable due to the present distribution of caries with the majority of children having no caries, while for a minority of children the caries experience still remains high [12].

Extending length between recall intervals is considered suitable due to the welldocumented caries decline in the child population [13]. It has been shown that extending length between recall intervals to 18-24 months in non-risk children has been without noticeable adverse effects on dental health [14]. The length of recall intervals has gradually been prolonged as an adjustment to reduced rate of caries progression [15-16], and to optimize the use of resources in the dental service [17].

There is lack of information about recall intervals between dental examinations practiced in child dentistry internationally and whether the recall routines influence the dental 
health in children. A recent meta-analysis concluded that evidence to support or refute the practice of fixed recall intervals was insufficient and that further studies are needed [1].

In Norway, all children from birth until the age of 18 years are by law entitled to individualized dental care in the public dental services free of charge according to the examiners assessment of caries risk. Nearly all children (97\%) visit the public dental services regularly. The statement requiring at least yearly visits to the dental clinic was removed from the law in the early 1980s [18]. Individualized and extended recall intervals have been recommended in child dental care during the last 30 to 40 years [19]. However, recommendations do not specify length between recall intervals. As caries is multifactorial and difficult to predict, intervals have in recent years been based on clinicians' assessment of each child's oral health, and not based on specific criteria.

The aim of the study was to follow attendance patterns longitudinally by exploring length between routine dental examinations in children at the ages of 5 and 12 years. In addition, the aim was to study associations between length of recall intervals and caries prevalence controlled for gender, parents' national background and education.

\section{Material and methods}

\section{Study population}

All children born in 2002 in one county in Norway $(n=7002)$ were invited to participate in the longitudinal study at 5 years of age. In total, 5623 children were included, of which 3282 children were available for re-examination at 12 years of age. Only children with complete data from both examinations were included. The final population consisted of 2960 children, $1537(52 \%)$ boys and 1423 (48\%) girls. At the first examination mean age was 5.2 years (SD 0.4 ) and at the second examination mean age was 12.1 years (SD 0.5). 


\section{Methods}

Information regarding length of recall intervals and caries experience was collected in conjunction with routine examinations performed by dentist and dental hygienist in the dental service. Data was obtained from dental records, by clinical and radiographic examination of children and questionnaires filled in by parents at the dental visits at age 5 years.

\section{Dental records}

A recall interval was defined as time between two routine examinations and specified in months. Interval since previous routine examination (previous interval) and planned interval to next routine examination (planned interval) were recorded at both ages. Previous and planned intervals were dichotomized into less than 18 months (short interval) and 18 months or more (long interval).

\section{Clinical examination}

The examinations were performed by dental hygienists and dentists in a fully equipped dental clinic using mirror and probe after teeth had been dried with air. Bitewings were taken of $68 \%$ and $99 \%$ of children at 5 and 12 years respectively. Caries was reported at tooth level. Teeth were registered and given codes according to status: sound, decayed, filled or missed due to caries. Lesions extending into dentine $\left(\mathrm{d}_{3} / \mathrm{D}_{3}\right)$ were reported as caries and children were categorized as having caries prevalence or not having caries prevalence.

\section{Intra- and interexaminer agreements}

Written and oral information about the clinical caries criteria was given to and discussed with the examiners before data collection started. Intra- and interexaminer agreements were calculated using Cohen's kappa [18]. A "gold standard" was developed based on the second and third authors' registrations and compared with the examiners' registrations. The examination at 5 years of age was performed by 44 hygienists. Intra-and interexaminer agreements were tested using 20 bitewing radiographs of deciduous molars including 8 
approximal surfaces in each radiograph. The mean intra- and interexaminer values were 0.85 (SD 0.12) and 0.86 (SD 0.10). The examination at 12 years of age was performed by 45 dentists and 46 hygienists. Intra- and interexaminer agreement was tested using 8 bitewing radiographs of permanent molars including 12 approximal surfaces in each radiograph. The mean intraexaminer and interexaminer values were 0.69 (SD 0.16) and 0.69 (SD 0.17). Cohen's kappa values was categorized as substantial to almost perfect [18]. In addition, the dental service has guidelines regarding caries registration and the dentists and hygienists are calibrated on regular basis as part of the routines in the dental service.

\section{Questionnaire}

Parents completed a questionnaire at the dental examinations. The questionnaire provided information about the children's gender, parents' national background and education.

Parents' background was registered as mother's and father's country of birth, combined into one variable and dichotomized into both parents having western background and one or both of non-western background. Non-western background included Asia, Africa, South America, Central America and Eastern Europa [19].

Parents' education was registered as mother's and father's length of education, combined into one variable and dichotomized into both parents having high education and one or both parents having low education. More than 12 years at school was defined as high education and 12 years or less at school was defined as low education.

\section{Ethical aspects}

Written informed consent was obtained from all parents. The study was approved by the Regional Committee for Medical Research Ethics (2.2006.54 and 2013/1881).

\section{Statistics}

The statistical analyses were performed using Statistical Package for the Social Sciences (SPSS, Inc. Chicago, IL, USA, version 24). Results were reported using frequencies, means, 
standard deviations and range. Data were cross-tabulated and differences tested using Chisquare statistics. Pearson's correlation coefficient was used to explore the association between recall intervals. Spearman's rank correlation was used to investigate collinearity between independent variables before multivariate analyses were conducted. Multivariate logistic regression analyses were conducted with previous and planned intervals at 5 and 12 years of age as dependent variables. Results were reported by odds ratios and $95 \%$ confidence intervals.

\section{Results}

Description of family characteristics and caries prevalence in children at the ages of 5 and 12 years is presented in Table 1. The majority of the children had two parents of western background and more than half of the children had both parents' with high education. Caries prevalence in children was low; at 5-years of age the majority and at 12 years of age twothirds were caries free.

(Table 1 near here)

In Figure 1 the lengths of previous and planned intervals at 5 and 12 years of age are presented. The most frequent used intervals were 12, 18, 20 and 24 months at both ages. At age 5 years about $80 \%$ of the children had intervals of 18 months or longer. At age 12 years $65 \%$ of the children had intervals of 18 months or longer. Nearly no children had planned intervals shorter than 12 months at 12 years of age.

(Figure 1 near here)

At 5 years of age mean previous interval was 20.2 months (SD 4.7) and ranged from 6 to 30 months, and mean planned interval was 18.2 months (SD 4.2) and ranged from 4 to 24 months. At 12 years of age mean previous interval was 18.2 months (SD 4.3) and ranged from 6 to 30 months, while mean planned interval was 17.2 months (SD 3.8) and ranged from 6 to 24 months. The differences between previous and planned intervals were small. Table 2 
shows correlations between previous and planned intervals at 5 and 12 years of age. Previous and planned intervals at both ages were associated $(\mathrm{p}<0.01)$, but the longitudinal associations between intervals at 5 and 12 years of age were weak.

Change in planned intervals from 5 to 12 years of age is presented in Figure 2. Among children with short intervals at 5 years of age half of the children (52\%) still had short intervals at the age of 12 years. Among children with long intervals at the age of 5 years, the majority $(72 \%)$ had long intervals at the age of 12 years.

(Figure 2 near here)

The bivariate associations between intervals at the ages of 5 and 12 years and children's caries prevalence, parents' background and parents' education is presented in Table 3. At both ages, recall intervals were associated with caries prevalence, parents' background and parents' education $(\mathrm{p}<0.05)$.

(Table 3 near here)

The four multivariate logistic regression analyses relating length of intervals at 5 and 12 years of age to caries experience controlled for gender, parents' background and parents' education is given in Table 4. The length of recall intervals was associated with caries experience at both ages. The probability of having short intervals was higher in children having caries experience than in caries free children. The length of recall intervals at 5 years of age was associated with parents' background and parents' education.

(Table 4 near here)

\section{Discussion}

This study aimed to explore the length of routine intervals in children and to study associations between recall intervals and children's caries experience controlled for family characteristics. The main results were that recall intervals were individualized, varied from 4 
to 30 months, and that most children at both ages were given recall intervals longer than 18 months. In addition, short recall intervals were associated with having caries experience.

In Norway, nearly all children are enrolled in the dental services which offer children and adolescents all treatment free of charge. The clinicians are salaried, suggesting that no economic incentives are given to either reduce or extend intervals. The dental service had the same guidelines regarding length of recall intervals and caries registrations at both ages, and calibration of clinicians showed substantial intra- and interexaminer agreement. Information regarding parents' background and education was collected by questionnaires. Although limitations are present in all questionnaire studies, the probability of recall and report errors was considered limited as these questions were unequivocal. In longitudinal studies, nonparticipation and drop-out may cause selection bias. In the studied children, caries prevalence, parents' background and educational level were similar to national average, thus it was reasonable to assume that the results were representative for the country in general [20-22].

The results showed that recall intervals were individualized and varied substantially. Length between examinations has been adjusted from previously standardized to individualized intervals concurrent with the polarization in children's dental health. As caries has declined in the child population, time spent for dental care has been reduced as a majority of children do not require operative dental care $[12,23]$. Targeting resources to high-risk individuals seems reasonable in this situation and indicate that dental care has been tailored to each child's need. Further, the results suggested adherence to national guidelines that recommend a risk approach and that length of intervals should be based on clinical assessment securing more frequent care to children with high risk of oral disease [24].

The results of this study showed that recall intervals were substantially longer than reported in previous studies $[8,14,25]$. Since early 1990 s mean recall intervals have been extended from 12 to about 18 months in Norway [9]. Similar trends have been observed in the 
other Nordic countries [26]. Extending intervals between examinations seems reasonable as the caries progression is documented to be slow [15]. Potentially, consequences of extending recall intervals in children at low caries risk may improve efficiency in the dental service. Resources saved by extending intervals for children with low risk may be transferred to children and groups in the population with high levels of disease and contribute to remove health inequalities. One study reported a tendency to spend longer time on routine examinations when children were examined less frequently which could reduce the efficiency of extended recall intervals [26]. Further studies are needed to assess this tendency.

The association between recall intervals at 5 and 12 years of age showed that the majority of children with long intervals at 5 years of age also had long intervals at 12 years of age, indicating that these children were identified as low risk children at both ages. One explanation may be that these children and their parents have succeeded in early establishment of favorable oral health behavior. It is known that established health behavior is resistant to changes and has long-term benefits [27-28]. Of the children that had short intervals at age 5 years, $50 \%$ also had short intervals at age 12 years, suggesting that the dental care delivered had failed to prevent caries development in these children. One-third of the children had a change in length of intervals between 5 and 12 years. Change in length of interval over time indicated that intervals were not standardized, but adjusted at dental visits based on caries risk assessment.

Recall intervals were associated with caries prevalence. The association between length of intervals and caries was stronger at 5 years than at 12 years of age. One explanation may be that risk indicators not included in this study, were considered by clinicians when planning recall intervals at 12 years of age [29]. The findings indicate that clinicians relied on caries risk assessment and children's caries status when planning length of intervals. 
Recall intervals were related to family characteristics at 5 and 12 years of age. This association was also stronger at 5 years than at 12 years of age. The findings indicated that dental personnel considered family characteristics to be more important in preschool children than in older children when deciding length of recall intervals. Cultural differences in parents' attitude towards oral health have been associated with higher probability of developing caries in preschool children with non-western background and parents with low education [30]. As the children grow older, they become more influenced by other factors such as friends and school, than by parents background and education [31]. A previous study has shown that young adolescents tend to follow their own opinions regarding oral health behavior and lifestyle independent of parents' attitude and background [32].

\section{Conclusions}

The length of recall intervals has significance for policy-makers, clinicians and patients. The rationale behind individualized recall intervals is to deliver dental care based on each child's need, and thereby obtain good oral health for all children, not to allocate equal amount of dental services to all. As a consequence of improved dental health and scarce resources it has been essential to optimize the efficiency in the dental service. This study showed that recall intervals were extended and individualized suggesting that resources were targeted on children with highest caries risk. This study indicated that clinicians mainly relayed on the caries situation, and to certain degree, family characteristics when the length of recall interval was tailored to the individual child. 


\section{Acknowledgements}

We thank the participants in the study and the Dental services in Akershus County for their cooperation.

\section{Disclosure of interest}

The authors declare no potential conflicts of interest with respect to the authorship and/or publication of this article. 


\section{References}

[1] Riley P, Worthington HV, Clarkson JE, et al. Recall intervals for oral health in primary care patients. Cochrane Database Syst Rev 2013;CD004346.

[2] Sheiham A. Is there a scientific basis for six-monthly dental examinations? Lancet 1977;2:442-4.

[3] American Academy of Pediatric Dentistry. Guideline on periodicity of examination, preventive dental services, anticipatory guidance/counseling, and oral treatment for infants, children, and adolescents.

[http://www.aapd.org/media/Policies Guidelines/G Periodicity.pdf]. Accessed 8 October 2018.

[4] National Institute for Clinical Excellence [NICE]. Dental checks: intervals between oral health reviews [https://www.nice.org.uk/guidance/cg19]. Accessed 8 October 2018.

[5] Lahti SM, Hausen HW, Widstrom E, et al. Intervals for oral health examinations among Finnish children and adolescents: recommendations for the future. Int Dent J 2001;51:57-61.

[6] Clarkson JE, Amaechi BT, Ngo H, et al. Recall, reassessment and monitoring. Monogr Oral Sci 2009;21:188-98.

[7] Lam S, Baros H, O'Grady M, et al. Patterns of attendance of children under 12 years at school dental service in Western australia. Open Dent J 2012;6:69-73.

[8] Helminen SK, Vehkalahti MM. Do check-up intervals correspond to caries indices in the free public dental service in Helsinki, Finland? Community Dent Health 2002;19:166-72.

[9] Wang NJ, Holst D. Individualizing recall intervals in child dental care. Community Dent Oral Epidemiol 1995;23:1-7.

[10] Källestål C, Flinck A, Allebeck P, et al. Evaluation of caries preventive measures. Swed Dent J 2000;24:1-11.

[11] Rose G, Khaw KT, Marmot M. Rose's strategy of preventive medicine. Revised edn. United States: Oxford University Press; 2008.

[12] Vehkalahti M, Tarkkonen L, Varsio S, et al. Decrease in and polarization of dental caries occurrence among child and youth populations, 1976-1993. Caries Res 1997;31:161-5.

[13] Marthaler TM. Changes in dental caries 1953-2003. Caries Res 2004;38:173-81.

[14] Wang NJ, Marstrander P, Holst D, et al. Extending recall intervals--effect on resource consumption and dental health. Community Dent Oral Epidemiol 1992;20:122-4.

[15] Mejare I, Stenlund H, Zelezny-Holmlund C. Caries incidence and lesion progression from adolescence to young adulthood: a prospective 15-year cohort study in Sweden. Caries Res 2004;38:130-41.

[16] Sheiham A, Maizels J, Cushing A, et al. Dental attendance and dental status. Community Dent Oral Epidemiol 1985;13:304-9.

[17] Seppa L. The future of preventive programs in countries with different systems for dental care. Caries Res 2001;35 Suppl 1:26-9.

[18] Landis JR, Koch GG. The measurement of observer agreement for categorical data. Biometrics 1977;33:159-74.

[19] Statistics Norway. Immigrants and Norwegian-born to immigrant parents [https://www.ssb.no/en/befolkning/statistikker/innvbef/aar]. Accessed 8 October 2018.

[20] Statistics Norway. Innvandreres bosettingsmønster. Innvandrere i bygd og by. [Distribution of the immigrant population]. [https://www.ssb.no/befolkning/artikler-og-

publikasjoner/innvandrere-i-bygd-og-by]. Accessed 8 October 2018.

[21] Statistics Norway. Caries prevalence at 5 and 12 years of age. [http://www.ssb.no/en/statbank/table/04163/tableViewLayout1/?rxid=473d317a-af1d4d15-8f06-f740892b9db4]. Accessed 8 October 2018.

[22] Statistics Norway. Educational attainment of the population. [https://www.ssb.no/en/utdanning/statistikker/utniv]. Accessed 8 October 2018. 
[23] Pitts NB, Boyles J, Nugent ZJ, et al. The dental caries experience of 5-year-old children in Great Britain (2005/6). Surveys co-ordinated by the British Association for the study of community dentistry. Community Dent Health 2007;24:59-63.

[24] Norwegian Directorate of Health. Tenner for livet. Helsefremmende og forebyggende arbeid [Teeth for life. Health promotion and health prevention].

[https://helsedirektoratet.no/Lists/Publikasjoner/Attachments/484/Tenner-for-livethelsefremmende-og-forebyggende-arbeid-IS-2659.pdf]. Accessed 8 October 2018.

[25] Wang NJ, Källestål C, Petersen PE, et al. Caries preventive services for children and adolescents in Denmark, Iceland, Norway and Sweden: strategies and resource allocation. Community Dent Oral Epidemiol 1998;26:263-71.

[26] Wang NJ, Petersen PE, Sveinsdottir EG, et al. Recall intervals and time used for examination and prevention by dentists in child dental care in Denmark, Iceland, Norway and Sweden in 1996 and 2014. Community Dent Health 2017;35:52-7.

[27] Wigen TI, Wang NJ. Does early establishment of favorable oral health behavior influence caries experience at age 5 years? Acta Odontol Scand 2015;73:1-6.

[28] Mattila ML, Rautava P, Aromaa M, et al. Behavioural and demographic factors during early childhood and poor dental health at 10 years of age. Caries Res 2005;39:85-91.

[29] Fisher-Owens SA, Gansky SA, Platt LJ, et al. Influences on children's oral health: a conceptual model. Pediatrics 2007;120:510-20.

[30] Wigen TI, Wang NJ. Caries and background factors in Norwegian and immigrant 5-year-old children. Community Dent Oral Epidemiol 2010;38:19-28.

[31] Skaret E, Espelid I, Skeie MS, et al. Parental beliefs and attitudes towards child caries prevention: assessing consistency and validity in a longitudinal design. BMC Oral Health $2008 ; 8$.

[32] Mattila ML, Rautava P, Paunio P, et al. Caries experience and caries increments at 10 years of age. Caries Res 2001;35:435-41. 
Figure 1. Length of previous and planned intervals in 5- and 12-year old children $(n=2960)$.

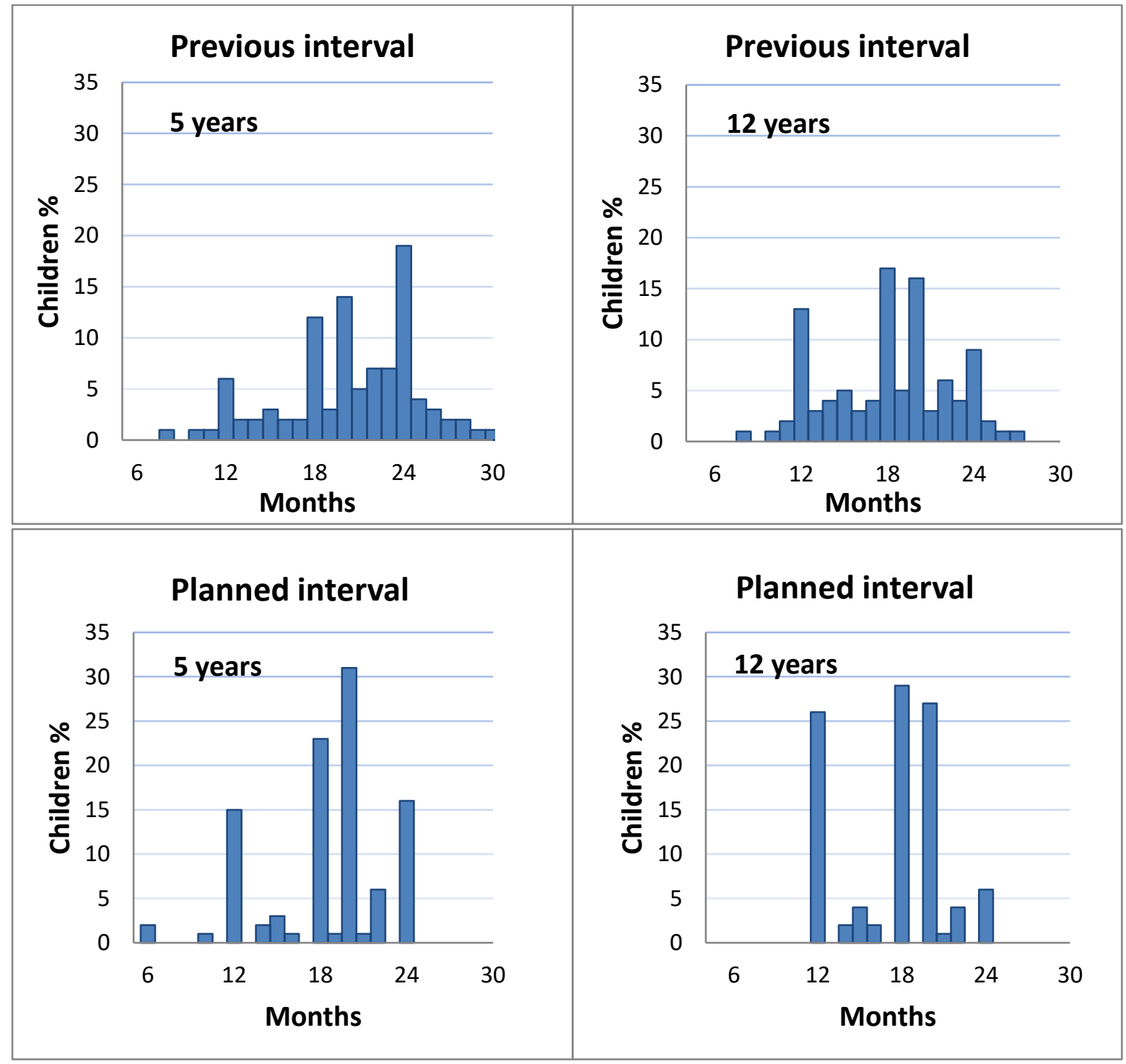


Figure 2. Change in planned intervals (shorter than 18 months or 18 months and longer) in children from 5 to 12 years of age $(n=2960)$.

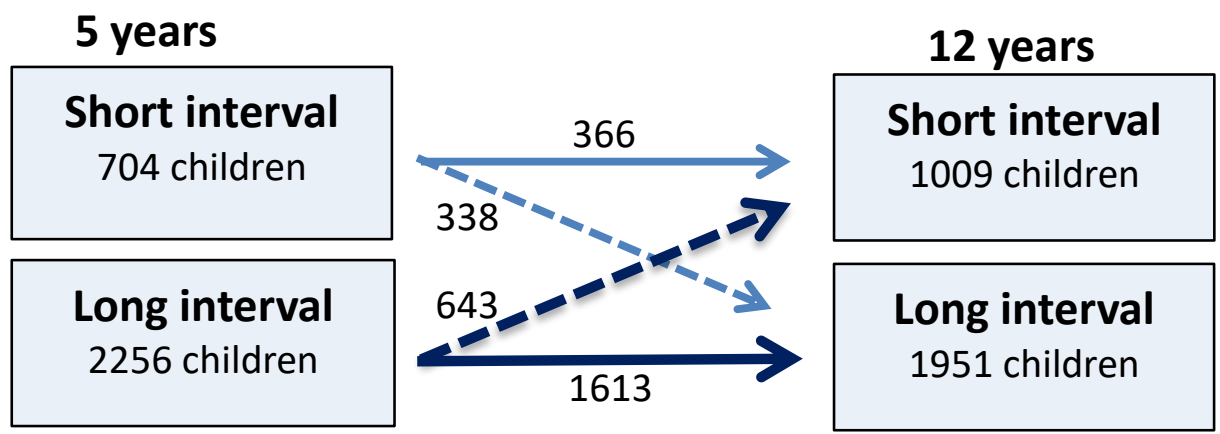


Table 1. Characteristics of the children $(n=2960)$.

(n) $\%$

\begin{tabular}{lr}
\hline $\begin{array}{l}\text { Gender } \\
\text { Girl }\end{array}$ & $(1423) 48$ \\
Boy & $(1537) 52$ \\
Parents' background & \\
Both western & $(2595) 88$ \\
One or both non-western & $(365) 12$ \\
Parents' education & \\
$\quad$ Both high & $(1709) 58$ \\
One or both low & $(1251) 42$ \\
Caries prevalence age 5 years & \\
$\quad$ No & $(2505) 85$ \\
$\quad$ Yes & $(455) 15$ \\
Caries prevalence age 12 years & \\
$\quad$ No & $(2005) 68$ \\
Yes & $(955) 32$ \\
\hline
\end{tabular}


Table 2. Correlations (Pearson's rho) between interval in previous routine examinations (previous) and interval in planned routine examinations (planned) at 5 and 12 years of age ( $n=2960)$.

\begin{tabular}{llllll}
\hline & \multicolumn{2}{c}{5 years } & \multicolumn{2}{c}{12 years } \\
\cline { 3 - 6 } & & Previous & Planned & Previous & Planned \\
\hline \multirow{2}{*}{5 years } & Previous & 1 & $\mathbf{0 . 4 7}$ & $\mathbf{0 . 1 5}$ & $\mathbf{0 . 1 8}$ \\
& Planned & 1 & $\mathbf{0 . 1 9}$ & $\mathbf{0 . 2 6}$ \\
12 years & Previous & & 1 & $\mathbf{0 . 4 9}$ \\
& Planned & & & & 1 \\
\hline
\end{tabular}

Statistically significant results marked in bold 
Table 3. Interval in previous routine examinations (previous) and interval in planned routine examinations (planned) at 5 and 12 years of age according to gender, parents' background, parents' education and children's caries prevalence $(n=2960)$.

\begin{tabular}{|c|c|c|c|c|}
\hline & \multicolumn{2}{|c|}{5 years } & \multicolumn{2}{|c|}{12 years } \\
\hline & Previous & Planned & Previous & Planned \\
\hline & Mean (SD) & Mean (SD) & Mean (SD) & Mean (SD) \\
\hline \multicolumn{5}{|l|}{ Gender } \\
\hline Girl (ref) & $20.2(4.7)$ & $18.6(4.2)$ & $18.3(4.3)$ & $17.3(3.7)$ \\
\hline Boy & $20.1(4.7)$ & $18.2(4.3)$ & $18.1(4.3)$ & $17.1(3.8)$ \\
\hline \multicolumn{5}{|l|}{ Parents' background } \\
\hline Both western (ref) & $20.4(4.5)$ & $18.7(4.0)$ & $18.4(4.3)$ & $17.3(3.7)$ \\
\hline One or both non-western & $18.0(5.7)$ & $15.9(4.9)$ & $17.3(4.5)$ & $16.3(3.9)$ \\
\hline \multicolumn{5}{|l|}{ Parents' education } \\
\hline Both high (ref) & $20.5(4.6)$ & $18.9(4.0)$ & $18.4(4.3)$ & $17.4(3.8)$ \\
\hline One or both low & $19.6(4.9)$ & $17.6(4.4)$ & $18.0(4.3)$ & $16.9(3.7)$ \\
\hline \multicolumn{5}{|l|}{ Caries prevalence } \\
\hline No (ref) & $20.8(4.2)$ & $19.3(3.6)$ & $18.5(4.3)$ & 17.5 (3.7) \\
\hline Yes & $16.8(5.9)$ & $13.4(4.0)$ & $16.6(4.1)$ & 15.6 \\
\hline
\end{tabular}

Statistically significant results marked in bold 
Table 4. Previous and planned intervals at 5 and 12 years of age according to gender, parents' background, parents' education and caries prevalence $(n=2960)$. Multivariate logistic regression. Odds ratios and $95 \%$ confidence intervals.

\begin{tabular}{|c|c|c|c|c|}
\hline & \multicolumn{2}{|c|}{5 years } & \multicolumn{2}{|c|}{12 years } \\
\hline & Previous & Planned & Previous & Planned \\
\hline & OR $(95 \% \mathrm{Cl})$ & OR $(95 \% \mathrm{Cl})$ & OR $(95 \% \mathrm{Cl})$ & OR $(95 \% \mathrm{Cl})$ \\
\hline \multicolumn{5}{|l|}{ Gender } \\
\hline \multicolumn{5}{|l|}{ Girl (ref) } \\
\hline Boy & $1.1(0.9-1.3)$ & $1.1(0.9-1.4)$ & $1.0(0.9-1.2)$ & $1.1(1.0-1.3)$ \\
\hline \multicolumn{5}{|l|}{$\begin{array}{r}\text { Parents' background } \\
\text { Both western (ref) }\end{array}$} \\
\hline One or both non-western & $2.9(2.3-3.7)$ & $1.8(1.4-2.4)$ & $1.4(1.1-1.7)$ & $1.2(1.0-1.6)$ \\
\hline \multicolumn{5}{|l|}{ Parents' education } \\
\hline \multicolumn{5}{|l|}{ Both high (ref) } \\
\hline One or both low & $1.4(1.2-1.7)$ & $1.3(1.0-1.5)$ & $1.1(0.9-1.2)$ & $1.1(0.9-1.2)$ \\
\hline \multicolumn{5}{|l|}{ Caries prevalence 5 years } \\
\hline \multicolumn{5}{|l|}{ No (ref) } \\
\hline Yes & & $12.6(9.9-16.0)$ & $2.3(1.9-2.8)$ & $1.8(1.4-2.2)$ \\
\hline \multicolumn{5}{|l|}{ Caries prevalence 12 years } \\
\hline \multicolumn{5}{|l|}{ No (ref) } \\
\hline Yes & & & & $2.7(2.3-3.1)$ \\
\hline
\end{tabular}

